\title{
ESRC-DFID Research for Policy and Practice: Women's life choices
}

\section{Foreword}

W omen contribute enormously to economies, whether by doing unpaid domestic work, agricultural work, or participating in businesses. Yet they often face tremendous challenges in their daily lives, such as difficulty in even having their voices heard or gaining a foothold in job markets. They are subject to violence and discrimination, lack of access to health-care services, and inequalities in education, which in turn impede them from accessing economic opportunities.

According to the Global Education Monitoring Report 2016 produced by UNESCO, 63 per cent of women who have not attained even minimal literacy skills live in rural areas in sub-Saharan Africa and Asia. In 2015, the United Nations Millennium Development Goals Report noted that the large majority of Africa's high rate of maternal deaths occur in the rural areas where only 56 per cent of births are attended by skilled personnel. These statistics alone paint a startling picture, showing that women, especially those in rural areas, are still disadvantaged despite decades of efforts and progress made to improve their lives.

This collection of ESRC-DFID-funded research identifies critical elements that are important to address if women's and girls' lives are to change for the better. The research looks at the mobility constraints experienced by girls and how a lack of access to means of transport hampers their access to paid work, health services, and schooling. It also identifies the barriers that women face when it comes to attending lifesaving diagnostic treatment or accessing maternal health-care services. Furthermore, it emphasises the significant role of education systems in not only enhancing women's economic opportunities but also in helping to bridge the gender gap by shaping young people's aspirations in their future career choices.

On the basis of this evidence, several key interventions have been identified that will transform the lives of women and girls, especially those in poor, rural, and marginalised populations. For instance, it is vital to find a way to increase the accessibility of disease diagnostic treatment. The research also highlights the value of using existing spatial data to tackle exclusion from health-care services. In addition, the research identifies the need to strengthen the relationships between school and community, teachers and learners, if we are to increase young women's life choices.
To achieve gender equality and empower all women and girls (Goal 5 of the 2030 Agenda for Sustainable Development), there has to be investment in research. However, for research to have an impact, it is critical that it is linked to policymaking. Research provides much needed evidence for policymakers to design policies and programmes as well as influence the allocation of the requisite resources.

This collective research supported by ESRC-DFID will no doubt contribute to the knowledge and evidence that policymakers need to address gender disparities and improve the lives of women and girls.

Adequate policies, programmes, and investments in women's health and education not only lift women's living standards but also pave a way towards gender equality. Unless women are equipped to reach their full potential and are empowered to make their own life choices, the 2030 Agenda Goals will be missed

\section{Thokozile Ruzvidzo}

Director of Social Development Policy Division

United Nations Economic Commission for Africa

\section{Key messages}

- Stronger consideration of gendered mobility needs is essential;

- Combine different types of evidence, for example spatial maps and interviews, to improve programme design with an understanding of local realities;

- Work with a range of actors, including being clear about their role as this often results in more meaningful and sustained networks and interventions;

- If education systems are to encourage young people to aspire to alternative futures, governments, donors and development agencies should focus on more than just providing educational resources, but should seek to bring together communities, teachers, and children to better understand the challenges faced by women and girls. 


\section{Access to transport is instrumental in shaping girls' lives}

Girls have much less access to means of transport than boys, which greatly limits their opportunities to go to school, receive health care, or get a paid job. Yet the mobility of girls is not an issue that figures often in development debates. Research led by young girls in subSaharan Africa (SSA) demonstrates the far-reaching implications of this for girls' lives and life-chances.

Far fewer girls ride bicycles than boys in SSA, mostly because of the lack of resources to buy a bicycle, household work demands, sexual innuendo, and community disapproval. Girls have less resources to pay transport fares, which is in part because household work limits their opportunities for wage employment, and they may suffer harassment if they do travel by taxi or minibus. There is a need to understand the context and constraints for the lack of access to transport for girls in SSA, as it remains one of the biggest barriers for girls to meaningfully participate outside of the home.

The Children, Transport and Mobility in Sub-Saharan Africa project (2006-10), led by Durham University, conducted studies across 24 sites in rural and urban Ghana, Malawi, and South Africa, in collaboration with Ghana's University of Cape Coast, the University of Malawi, and South Africa's Council for Scientific and Industrial Research (CSIR). The project's aim was to discover how boys' and girls' daily physical mobility affects their access to goods, services and life-chances, and to inform policymakers and practitioners, especially those working in the transport sector. Schoolchildren between 11 and 19 years old made key inputs, not only as respondents but as co-investigators. They held interviews with their peers aged 9-18, while walking to school, at water points and markets, during firewood collection, and at play. They provided insights that we simply would not have uncovered otherwise.

Comparison of girls' and boys' movement patterns helped the researchers to identify constraints experienced by girls, and focus on interventions that may mitigate them. The project identified that mobility is more than a technical issue, it is a cultural one as well. Girls are regularly considered as vulnerable and too incompetent and naive to be allowed to travel alone. This significantly affects their access to paid work, health services, education, social networks, leisure, and wider wellbeing. There are several 'life' implications that come from the lack of mobility and access to transport for girls in SSA:

- Domestic labour: The shortage of cheap, reliable, regular transport in Africa and common absence of water pipes and electricity puts a particular burden on girls as they inevitably bear the brunt of carrying water and firewood for domestic use. Cultural expectation to participate in domestic work also means that girls are less likely to continue in schooling or to do paid work.

- Schooling: Parental concerns around girls' travel safety and vulnerability mean they may start school later than boys and are far less likely to attend secondary school, which generally requires longer journeys.

- Paid work: Concerns regarding girls' independent travel (sometimes including perceptions that they are potentially promiscuous) reduce their access to paid work opportunities beyond the home settlement.

- Health: Girls report more need for access to health services than boys, especially in the context of teen pregnancy. Their lack of resources to pay for transport can have serious implications, especially when obstetric emergencies occur.

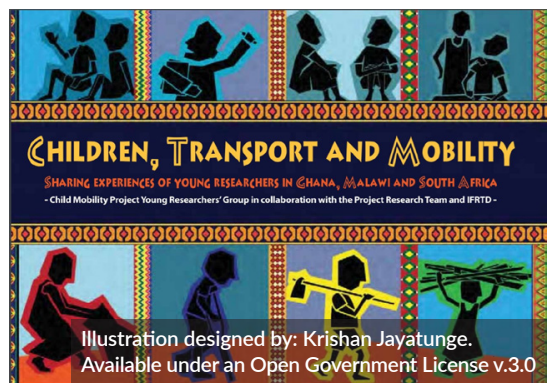

Based on this evidence, the researchers have worked with government, non-governmental organisations (NGOs), and the private sector to help address these issues in-country. This included working with the Ghana Education Service to bring gendered mobility issues into teacher training and the school curriculum. The team also informed transport training manuals produced by the African Community Access Programme for policymakers and practitioners across the continent as well as training sessions and draft guidelines for gender mainstreaming prepared for the African Development Bank's transport division.

The evidence demonstrates how constraints on girls' and women's mobility and access to services are pervasive and have far-reaching implications. There are many interventions that could improve girls' mobility and access to key services, such as improved school boarding provision for girls, reduction of domestic load-carrying (through improved water supply, solar energy uptake, and fuel-efficient stoves), and a stronger consideration of gendered mobility needs by the transport sector. However, most fundamental of all is the need for a reduction of gender-based violence and improvements in female status. In many parts of Africa, NGOs are now leading efforts, but increased training and community dialogue are essential to bring about this change. This research highlights the enormity of this task and reinforces the need for more to be done if significant change is to be possible.

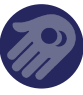

Project title: Children, transport and mobility in sub-Saharan Africa: developing a child-centred evidence base to improve policy and change thinking across Africa.

\section{Gina Porter}

Senior Research Fellow, Department of Anthropology Durham University, UK

The study took place in partnership with collaborators in Ghana (Albert Abane), Malawi (Alister Munthali and Elsbeth Robson) and South Africa (Mac Mashiri); Kate Hampshire (Durham University) worked across all contexts.

\section{SEE ALSO:}

Porter, G. (2011)'I Think a Woman Who Travels a Lot is Befriending Other Men and That's Why She Travels': Mobility Constraints and their Implications for Rural Women and Girls in Sub-Saharan Africa', Gender, Place \& Culture 18.1: 65-81

Porter, G. et al. (2017) Young People's Daily Mobilities in Sub-Saharan Africa: Moving Young Lives, London: Palgrave Macmillan

Porter, G. et al. (2012) 'Child Porterage and Africa's Transport Gap: Evidence from Ghana, Malawi and South Africa', World Development 40.10: 2136-54
Porter, G. et al. (2011) 'Mobility, Education and Livelihood Trajectories for Young People in Rural Ghana: A Gender Perspective', Children's Geographies 9.3-4: 395-410

A list of published papers and other documents from the project is available on the project website: www.dur.ac.uk/child.mobility/ 


\section{Maternal health in Ghana: Why geography matters}

Improving maternal health is an agreed international development goal. Ghana is a country with a high level of maternal mortality but where rapid enhancement of services is underway. Exclusion from maternity care is a matter of geographical inaccessibility and low status/poverty. Research carried out by the University of Southampton from 2008 to 2011 provided policymakers and women themselves with spatial data to tackle exclusion through maps and other evidence that promoted accountability, as well as information and insight.

Despite maternal health being high on the agenda of the government and international community, Ghana was struggling to make progress on improving maternal health under Millennium Development Goal 5. The Poverty and Maternal Health in Ghana project used existing geodata to spatially analyse the relationship between poverty and poorly utilised maternal health services in Ghana, and informed the government, funders, development agencies, and civil society of issues associated with accessing maternal health care and where services and interventions should be targeted to improve maternal health.

It was a collaboration between Northern and Southern-based researchers, government analysts, local and international civil society, and non-governmental organisations working in the fields of demography, health, and geography.

The research highlighted that distance from health-care services is a key exclusionary factor in rural Ghana, regardless of women's education, ethnicity, and their household wealth status.

Furthermore, at the community level, the research found that encouraging women to attend antenatal care and empowering them with information about available services can be as important for access to health care as the poverty level in the community itself.

The project used geographic information systems (GIS) in two case study regions. This use of high-precision data enabled them to quantify 'access to services' much more accurately than before. The model took into account the effect of the local road and footpath network; natural barriers to access such as rivers, swamps, and enclosed areas; and local gradient and topography.

The project had an impact on the GIS research capacity in Ghana through the training of local researchers in both academia and government. This was particularly useful in the government sector, where geodata has since helped to prioritise resources.

The researchers, from the disciplines of public health, social policy, geography, and demography worked in participatory ways from the start of the project. Working together they built strong links between women and their health-care services; they also promoted close collaboration with the Government of Ghana to exert direct influence on diverse stakeholders interested in maternal wellbeing and survival.

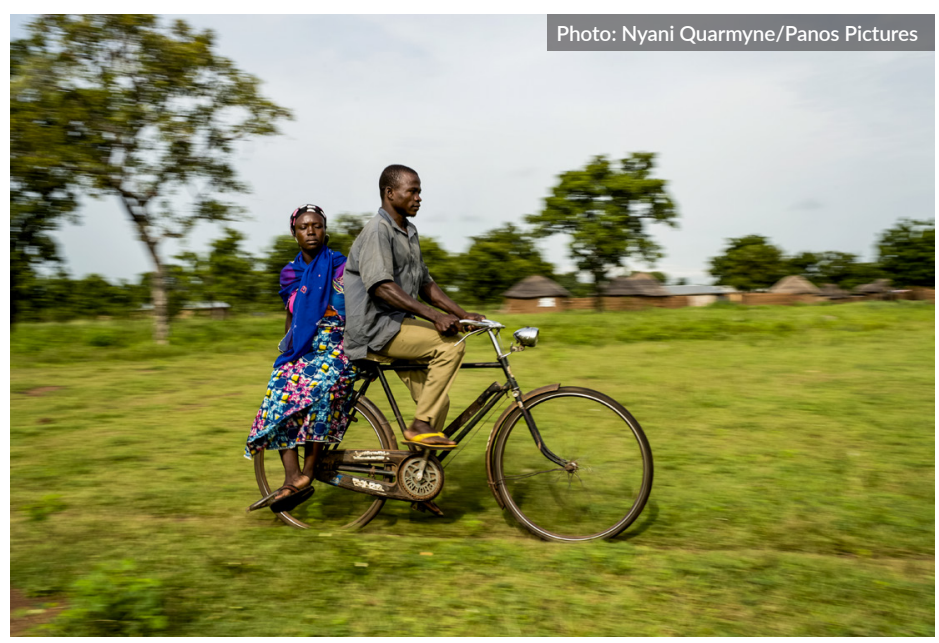

Ghana, Nyologu, Northern Region: Sanatu Issahaku, heavily pregnant, on the back of her husband's bicycle in the village of Nyologu. Poor road infrastructure and long distances make it difficult for women like Sanatu to access healthcare.

Key Ghanaian academics working in the field of maternal health have also been engaged in research dissemination efforts. In particular, the work has been taken up by colleagues in the School of Public Health, University of Ghana. Methodologically, the work has been influential in the Ghana Statistical Service.

Following the experience of working more closely with geographers on GIS in maternal health, some members of the research team are now working in national positions in Ghana as well as in international agencies. The dissemination of materials linked to the Atlas of Birth has also been influential, a project which has launched a live website with information on maternal and newborn health for every country in the world, including the launch of a specific Ghanaian atlas.

The research team continues to actively engage with key policy actors in the region, impacting on the reform agenda in Ghana in terms of public health policy, and also accountability, campaigning, and advocacy actions that are empowering women to access health care.

Project title: Poverty and maternal health in Ghana: a spatial analysis of exclusion from care.

\section{Zoe Matthews}

Professor of Global Health and Social Statistics

University of Southampton, UK

\section{SEE ALSO:}

Gething, P. (2010) 'Too Far to Walk: Callibrating Distances to Maternity Health Facilities for Women Delivering in Ghana Using GIS', Conference Proceeding Abstract

Johnson, F.A. and Madise, N.J. (2010) 'Targeting Women at Risk of Unintended Pregnancy in Ghana: Should Geography Matter?', Sexual \& Reproductive Healthcare 2.1: 29-35
Kehoe, S.; Neilson, J.P. and Norman, J.E. (eds) (2010) Maternal and Infant Deaths: Chasing Millennium Development Goals 4 and 5, London: RCOG Press 


\section{Schools, society, and rural girls' aspirations}

Schooling plays a core role in shaping the life-choices of many young women worldwide. Education systems are focused on the future both national and individual - and going to school is often understood by teachers, parents, and students alike as preparation for a future life. Many aspects of schooling explicitly encourage young people to aspire to certain sorts of (gendered) future, yet the links between schooling and aspiration are not well understood.

In 2017, researchers from Brunel University London and the International Institute of Social Studies, The Hague, worked with rural primary schools and their surrounding communities in Lesotho, India, and Laos. They wanted to know what role education systems play in shaping young people's aspirations in remote rural areas.

Nine months of ethnographic research was undertaken in two communities in each setting: Korba District in Chhattisgarh, India; Oudomxay Province, Laos; and rural Lesotho. Here the team sought to develop a robust understanding of the mechanisms that connect schooling, aspirations and learning outcomes, and to develop ways to better capture these approaches and learn from them. They examined curricula and textbooks, but also the ways these are used in the classroom; messages conveyed through other aspects of schooling; and the ways in which children respond.

In Lesotho and Laos, the researchers found that texts used in the classroom explicitly address the gendered career opportunities that face young people, encouraging them to aspire to futures not traditionally associated with their own gender. They do not, however, tell a consistent story. In Laos, textbooks tend to represent girls and boys, men and women, in equal numbers to suggest balance, and sometimes challenge stereotypical expectations when it comes to careers. However, teachers are usually depicted as female and the 'naughty' child is almost invariably male.

In Lesotho, the example of Malala Yousafzai, the Pakistani activist for female education and the youngest Nobel Prize laureate, is used to suggest the need to struggle for gender equality. However, a few pages later in the same book, adolescence is discussed in terms that suggest gender differences are biologically determined, while depictions of careers seldom challenge expectations.

The Indian primary school textbooks do even less to confront gender inequalities. Rather, they depict and describe the life stories of (male) nationalist leaders, emphasising their role in addressing class or caste inequalities as opposed to reforming gender attitudes.

It is important to recognise the differences in representation and how they are constructed, as these have an impact on children's lifechoices and motivations. The representations of possible futures that children encounter in the classroom are produced through the interaction of national and international actors and reflect aspirations of governments and agencies. But teachers also play an important role in shaping aspirations, and children themselves do not passively absorb what is presented to them. Rather, they interpret what they see and hear in light of their wider social and economic lives.

Notably, Lesotho has introduced a new integrated primary curriculum which is radically different from those in India or Laos. It pays much greater attention to non-formal rural livelihoods, life skills, and planning for the future - areas that might be expected to widen the choices available to rural girls. Lesotho's textbooks, however, give emphasis to (and illustrate) limited parts of the curriculum, and teachers are selective in what they teach, focusing on topics and pedagogies they are most familiar with. Children, in turn, attend to only limited parts of what is presented to them.

Irrespective of different curricula, most children in all three settings saw education as a pathway only to a small range of genderstereotyped formal sector careers (nurse, teacher, police, soldier). Yet, these expressed aspirations were often held superficially: the children were not consistent over time. Moreover, lacking significant exposure to adults in these occupations, they had little idea about how to achieve them or what life would be like were they successful.

This research is providing an important evidence-based contribution to show how aspirations are produced relationally, between school and community and between teachers and learners. While aspiration may play a role in social change, including the transformation of gender relations, efforts to promote 'gender-neutral' or transformative aspirations are reinterpreted through numerous iterations within the school system. Changes in the formal curriculum alone have limited impact, given the powerful roles played by teachers (particularly in rural areas) in determining what and how to teach, as well as children's own expectations, shaped by their families and communities.

The research identifies that if education systems are to encourage young people to aspire to alternative futures, and to view school as a route to achieve alternative (rural) livelihoods, interventions should target the relationships between school and community, and between teachers and learners. The research team continues to work with policymakers, curriculum developers, and teacher educators in the three countries to consider possible interventions. Discussions of the findings with students, teachers, and parents have been fed into policy workshops at a mix of district, state, and national levels in each setting.

\section{Nicola Ansell}

Professor of Human Geography

Brunel University London, UK 


\section{Improving women's access to tuberculosis diagnosis services}

Since 2000, access to tuberculosis (TB) diagnosis has saved over 53 million lives (WHO 2018), but it still remains one of the world's biggest killers. TB diagnosis relies on patients attending diagnostic centres, which requires travel and staying several days. This presents a challenge for women in poor areas who, as the main caregivers, may not be able to leave children or elderly relatives for the duration, or who cannot get transport on their own to the clinic due to cultural constraints.

In 2009, the World Health Organization (WHO) adopted policies that supported approaches to reduce the time to make a TB diagnosis. The ESRC-DFID-funded research looked specifically at the barriers to diagnosis and treatment in Ethiopia, Yemen, and Nigeria, with a specific focus on women's and men's different experiences. In these countries, patients often abandon the diagnostic process and fail to initiate treatment.

Through surveys, interviews, and group discussions the research team tried to understand the participants' personal perceptions of diagnostic and treatment processes, the barriers they faced, and how services could be modified to improve access. There were significant costs involved, especially for clinic fees and transport, and among accompanied adults and those from rural areas.

While many participants explained that women had the same access to health care as men, in reality women faced additional difficulties to attend the services. These barriers included having to request permission from their husband, being unable to travel alone or to access household funds, and holding caring responsibilities.

The participants of this research, particularly women, attended the diagnostic services with companions and were often unprepared for the duration of the process. There were numerous reasons why many patients did not complete the diagnosis, including:

- The cost of the process

- Receiving negative but incomplete smear results

- Having a clear chest X-ray on the first day and then receiving misleading, or misinterpreting, information from staff.

These reasons were exacerbated in some settings where some patients had to pay additional unofficial fees and were often referred to private services. Patients found non-TB medication and additional tests in the private sector prohibitive. Many patients highlighted opportunity costs for diagnosis and treatment as an important obstacle. In response, the researchers developed models to identify populations at risk of high expenditure and ways to support those that are the most marginalised to access the services.

As a follow-on from the findings of the ESRC-DFID-funded research, TB REACH grants in Ethiopia, Yemen, and Nigeria have tested-out strategies to address the barriers that both men and women face through bringing diagnosis closer to households and communities. In Ethiopia, the TB REACH process trains village-based health extension workers (HEWs) to facilitate access to diagnosis, reducing travel and time taken to seek diagnosis and opportunity costs. This approach has doubled TB diagnosis, with significant increases amongst women.

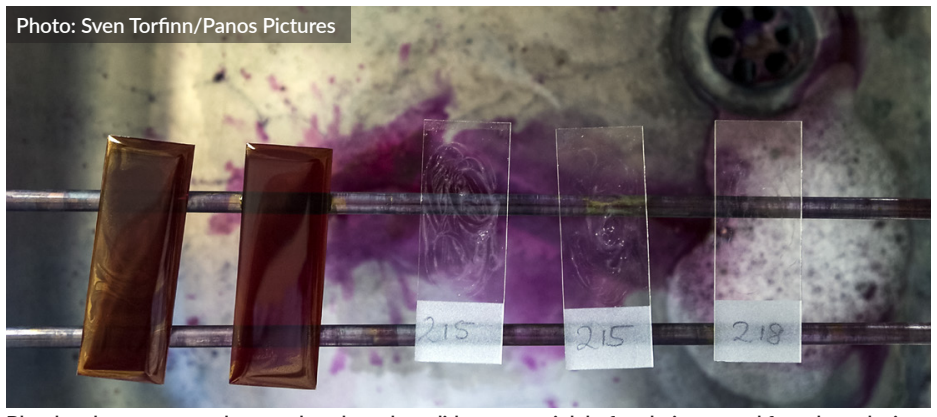

Blood and sputum samples are placed on glass slides over a sink before being tested for tuberculosis.

In Yemen, the TB REACH project followed-up with contacts of TB patients by visiting households to identify those close to them who had not accessed diagnostic services. These included the elderly, women, and children. The project identified that one in ten households had a second person with TB who had not accessed the services. In the Nigerian TB REACH process, HEWs identified adults with symptoms of TB in the congested informal settlements of Abuja and provided diagnostics for TB and HIV where they lived.

Patients in poor communities still face many barriers when it comes to attending and completing TB diagnosis. These barriers disproportionally affect women and are mediated by traditional and cultural norms including, for example, who is able to travel on their own. New approaches to TB diagnosis can help patients by reducing costs; the research shows how vital it is to find ways to complete the diagnosis process in one day and/or bring the treatment closer to where patients live.

Partnership with community health workers has made TB diagnostic and treatment services more accessible to the poor, women, the elderly, and children. Not only was placing TB services within communities much more hospitable and acceptable to families with poor access to health facilities, but all providers were also motivated by the clear use of the services so close to home.

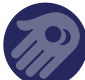

Project title: Identifying barriers to TB diagnosis and treatment under a new rapid diagnostic scheme.

\section{Sally Theobald}

Chair in Social Science and International Health

Liverpool School of Tropical Medicine, UK

\section{Luis Cuevas}

Chair in International Public Health and Epidemiology

Liverpool School of Tropical Medicine, UK

The study took place in partnership with researchers in Ethiopia (Mohammed Yassin and Daniel Gemechu Datiko), Yemen (Najla Al-Sonboli and Nasher Al-Aghbari) and Nigeria (Lovett Lawson); Rachel Anderson de Cuevas worked across all contexts.

\section{SEE ALSO:}

Anderson de Cuevas, R.M. et al. (2014) 'Barriers to Completing TB Diagnosis in Yemen: Services Should Respond to Patients' Needs', PLoS ONE 9.9: e105194

Datiko, D.G. et al. (2015) 'Exploring Providers' Perspectives of a Community Based TB Approach in Southern Ethiopia: Implication for Community Based Approaches', BMC Health Services Research 15.1: 501

Tulloch, O. et al. (2015) 'Patient and Community Experiences of Tuberculosis Diagnosis and Care Within a Community-Based Intervention in Ethiopia: A Qualitative Study', BMC Public Health 15: 187

Yassin, M.A. et al. (2013) 'Innovative Community-Based Approaches Doubled Tuberculosis Case Notification and Improve Treatment Outcome in Southern Ethiopia', PLoS ONE 8.5: e63174

WHO (2018) Tuberculosis, World Health Organization 


\section{THE IMPACT INITIATIVE}

For International Development Research

This summary highlights the key messages from research focusing on women's life choices from the ESRC-DFID Joint Fund for Poverty Alleviation and Raising Learning Outcomes in Education Systems Research Programme, and is an output of the Impact Initiative for International Development Research.

It is written in collaboration with research teams and edited by Kelly Shephard and Vivienne Benson, the Impact Initiative Communications team based at the Institute of Development Studies.

The Impact Initiative seeks to connect policymakers and practitioners with the world-class social science research supported by the ESRC-DFID Strategic Partnership, maximising the uptake and impact of research from: (i) the Joint Fund for Poverty Alleviation Research; and (ii) the Raising Learning Outcomes in Education Systems Programme. We seek to identify synergies between these programmes and their grant holders, support them to exploit influencing and engagement opportunities, and facilitate mutual learning. The Impact Initiative is a collaboration between the Institute of Development Studies (IDS) and the University of Cambridge's Research for Equitable Access and Learning (REAL) Centre.

Email: info@theimpactinitiative.net

Website: www.theimpactinitiative.net

y@the_Impact Init \#impactlessons

All content is available under the Open Government License v3.0, except where otherwise stated

Joint Fund for Poverty Alleviation: aims to enhance the quality and impact of social science research, addressing the key international development goal of reducing poverty amongst the poorest countries and peoples of the world.

Raising Learning Outcomes in Education Systems Programme: aims to provide policymakers and practitioners with concrete ideas on how to improve

$\mathrm{E} \cdot \mathrm{S} \cdot \mathrm{R} \cdot \mathrm{C}$ ECONOMIC \& S OCIAL RESEARCH C OUNCI L

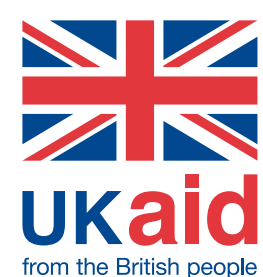

Research jointly supported by the ESRC and DFID 